OPEN ACCESS

Edited by:

Junli $X u$,

University College Dublin, Ireland

Reviewed by:

Ya-Fang Shang,

Hefei University of Technology, China Adele Papetti,

University of Pavia, Italy

*Correspondence:

Jiayan Zhang

jiayanzhang1988@163.com

Specialty section: This article was submitted to Nutrition and Food Science

Technology,

a section of the journal

Frontiers in Nutrition

Received: 13 October 2021 Accepted: 29 December 2021

Published: 10 February 2022

Citation:

Xiao X, Li J, Xiong H, Tui W, Zhu Y and

Zhang $J$ (2022) Effect of Extrusion or

Fermentation on Physicochemical and

Digestive Properties of Barley Powder.

Front. Nutr. 8:794355.

doi: 10.3389/fnut.2021.794355

\section{Effect of Extrusion or Fermentation on Physicochemical and Digestive Properties of Barley Powder}

\author{
Xiang Xiao ${ }^{1,2}$, Jiaying Li $^{1}$, Hao Xiong ${ }^{1}$, Wenxuan Tui ${ }^{1}$, Ying Zhu ${ }^{1}$ and Jiayan Zhang ${ }^{1 *}$ \\ ${ }^{1}$ School of Food and Biological Engineering, Jiangsu University, Zhenjiang, China, ${ }^{2}$ State Key Laboratory of Food Science \\ and Technology, Jiangnan University, Wuxi, China
}

In this work, the effect of extrusion and fermentation on the physicochemical and digestive properties of barley powder was studied. The results showed that the contents of phenolics, $\beta$-glucan, protein, and lipid decreased after extrusion. The contents of nutrients (except lipid) increased after fermentation. Both extrusion and fermentation of barley can lead to the darkening of the color and effectively optimize the palatability by reducing the viscosity. In vitro digestion of starch showed that the content of as rapidly digestible starch increased after extrusion and fermentation. The contents of ferulic acid, 2-hydroxybenzoic acid, and caffeic acid decreased after extrusion, while the contents of chlorogenic acid, p-coumaric acid, and ferulic acid increased after fermentation. Basically, the content of all the phenolic showed an increasing trend after digestion. The antioxidant activity decreased after extrusion and increased after fermentation. Therefore, the nutritional composition and properties of barley powder were changed under the two processing methods.

Keywords: extrusion, fermentation, rheological properties, digestive properties, antioxidant activity

\section{INTRODUCTION}

In recent years, metabolic syndrome, represented by obesity, hyperglycemia, hyperlipidemia, and diabetes mellitus, has become one of the most important non-communicable chronic diseases affecting human health. Barley is a new type of health food, whose overall nutritional index meets the requirements of high plant protein, high vitamin, high cellulose, low fat, and low sugar proposed by modern nutrition science. In addition, as a grain with a low glycemic index, barley can also be used to prevent chronic diseases such as diabetes and obesity (1).

Extrusion can greatly improve the digestibility of nutrients. Due to the short duration of the processing of food raw materials, the harmful effects of browning and nutritional damage on the nutrients of the raw materials are reduced to a large extent. Extrusion is a common processing method in the food industry, and it has the advantages of high production efficiency, simple process, low energy consumption, and low cost.

Fermentation is an effective method to improve the quality of barley. Lactobacillus plantarum is a common probiotic in food and it can regulate human cholesterol, blood pressure, and intestinal microorganism. Fermentation of barley using Lactobacillus plantarum can improve the nutritional value of barley and also can reduce the content of phytic acid. Therefore, the combination of Lactobacillus plantarum fermentation with barley is beneficial to improve its functional active components and enhance its physiological and nutritional functions (2). 
This paper mainly studied the effects of extrusion and fermentation treatments on the nutrient composition, rheological, and digestive properties of barley powder, and analyzed the advantages and disadvantages of these changes.

\section{MATERIALS AND METHODS}

\section{Materials and Reagents}

Yangzhou's No. 3 Barley Powder (BP) was purchased from Yancheng Shuangzeng Agrochemical Technology Co. LTD (Yancheng, China). Extruded Barley Powder (EBP, $40 \mathrm{~Hz}$ of screw rotation, $30 \mathrm{~Hz}$ of feeding speed, $140^{\circ} \mathrm{C}$ of sleeve temperature, and $30 \%$ of raw water content) and fermented barley powder (FBP, fermentation with Lactobacillus plantarum dy-1) were prepared in our laboratory.

$\alpha$-amylase, glucosidase, pepsin, trypsin, and bile salt were purchased from Sigma Company (St. Louis, MO, United States) as biological reagents. Gallic acid, catechin, epicatechin, chlorogenic acid, ferulic acid, caffeic acid, 2-hydroxybenzoic acid, p-coumaric acid, vanillin acid, and 3, 4-dihydroxybenzoic acid were purchased from Tixi Ai (Shanghai) Chemical Industrial Development Co, Ltd.

\section{Determination of Nutritional Components Determination of Total Phenolics}

The total phenolic content was determined by the method described by Rani et al. (3) with some modifications. Briefly, $1 \mathrm{ml}$ of sample extract was diluted with $5 \mathrm{ml}$ water and $3 \mathrm{ml}$ of $\mathrm{Na}_{2} \mathrm{CO}_{3}$ (7.5\%) was added. Subsequently, the test tube was kept for $90 \mathrm{~min}$ incubation in the $45^{\circ} \mathrm{C}$ water bath and absorbance was measured at $750 \mathrm{~nm}$. A Gallic acid standard curve was made to determine the phenolic content.

\section{Determination of $\beta$-Glucan}

$\beta$-Glucan content was determined by the method described by 4 with some modifications. Briefly, $0.5 \mathrm{ml}$ of sample extract was diluted with $1.5 \mathrm{ml}$ water and $4 \mathrm{ml}$ of Congo red solution was added. Subsequently, the test tube was kept for $10 \mathrm{~min}$ incubation in the $20^{\circ} \mathrm{C}$ water bath and absorbance was measured at $550 \mathrm{~nm}$. A $\beta$-glucan standard curve was made to determine the $\beta$-glucan content.

\section{Determination of Protein Content}

The total nitrogen content was estimated by an azotometer (Milan, Italy). The protein content was calculated with the conversion factor of 6.25 .

\section{Determination of Fat Content}

The fat content was determined by following the AOAC (2006) standard method number 2003.05.

\section{Determination of Free Amino Acid Content}

The content of free amino acids was determined by the amino acid analyzer according to the method of $\mathrm{Hu}$ et al. (5). The results were expressed as the percentage of each amino acid in the total amino acids with the exception of tryptophan.

\section{Dissolving Characteristics and Rheological Characteristics \\ Determination of the Color}

The colors of barley samples were determined using the HunterLab UltraScan Pro according to the method described by Morris et al. (6) with some modifications. The $\mathrm{L}^{*}$ value represents the lightness, $0-100$ represents dark to light. The $a^{*}$ value represents the degree of the red-green and the $b^{*}$ value represents the degree of the yellow-blue.

\section{Determination of WSI and WAI}

The water solubility index (WSI) and water absorption index (WAI) were measured by the method of Haoqiang Wang et al. (7), with some modifications. A total of $2.5 \mathrm{~g}$ of samples were dispersed in $30 \mathrm{ml}$ distilled water and shaken in the water bath at $30^{\circ} \mathrm{C}$ for $30 \mathrm{~min}$, then centrifuged at $7000 \times \mathrm{g}$ for $15 \mathrm{~min}$. The weight of the sediment was taken as WAI and was expressed as the unit g/g. The WSI is the weight of dry solids in the supernatant, which is expressed as a percentage of the original weight of the sample.

\section{Determination of Pasting Properties}

Pasting properties were determined by the method described by $\mathrm{H}$. Wang et al. (8) with some modifications. Briefly, the pasting properties of samples were measured by a rapid viscoanalyzer (RVA) combined with the Thermocline for Windows $\left(\mathrm{TCW}_{3}\right.$ ) software. The basic weight of the sample was $3 \mathrm{~g}$ (on a raw basis) and was automatically corrected to a moisture basis of $14 \%$. Approximately, $3.0 \mathrm{~g}$ of samples and $25 \mathrm{ml}$ of distilled water were directly added into an RVA canister. Then, the slurry was homogenized manually by the plastic paddle to avert lumps formation prior to the RVA run. The canister with the sample and paddle was inserted into the RVA Instrument and the analysis was started. The samples were heated from 50 to $95^{\circ} \mathrm{C}$ with a heating rate of $12^{\circ} \mathrm{C} / \mathrm{min}$, maintained at $95^{\circ} \mathrm{C}$ for $3.5 \mathrm{~min}$, and then cooled to $50^{\circ} \mathrm{C}$ at the same rate and maintained at $50^{\circ} \mathrm{C}$ for $5 \mathrm{~min}$. The following characteristics were then evaluated: peak viscosity, trough viscosity, final viscosity, breakdown, setback, peak time, and pasting temperature.

\section{Static Viscoelasticity Analysis}

The efficacy of barley in lowering blood lipid and cholesterol is closely related to its viscosity. The rheological property of the sample can be further analyzed by measuring the static viscoelasticity. Viscoelastic measurements were performed using a TA rheometer equipped with parallel plate geometry $(40 \mathrm{~mm})$. Firstly, $0.6 \mathrm{~g}$ sample was dissolved in $10 \mathrm{ml}$ distilled water and mixed to prepare the solution with $6 \%$ concentration. After the fixture was installed and the calibration was carried out, about $1.5 \mathrm{ml}$ sample solution was taken and dropped in the center of the plate. A frequency sweep test for starch gels was performed at $25^{\circ} \mathrm{C}$ from 0.01 to $1,000 \mathrm{~s}^{-1}$ within the linear viscoelastic range.

\section{In vitro Starch Digestion}

The digestibility of starch was determined according to the procedure, as follows. First, $0.2 \mathrm{M}$ sodium acetate buffer $(\mathrm{pH}$ 6.0 containing $200 \mathrm{mM}$ calcium chloride, $0.49 \mathrm{mM}$ magnesium 
TABLE 1 | Preparation of stock solution of simulated digestion fluids.

\begin{tabular}{lcccc}
\hline & Concentration (M) & SSF (mM) & SGF (mM) & SIF (mM) \\
\hline $\mathrm{KCl}$ & 0.50 & 18.88 & 8.63 & 8.50 \\
$\mathrm{KH}_{2} \mathrm{PO}_{4}$ & 0.50 & 4.63 & 1.13 & 1.00 \\
$\mathrm{NaHCO}_{3}$ & 1.00 & 17.00 & 31.25 & 106.25 \\
$\mathrm{NaCl}$ & 2.00 & - & 59.00 & 48.00 \\
$\mathrm{MgCl}_{2}\left(\mathrm{H}_{2} \mathrm{O}\right)_{6}$ & 0.15 & 0.19 & 0.13 & 0.41 \\
$\left(\mathrm{NH}_{4}\right)_{2} \mathrm{CO}_{3}$ & 0.50 & 0.08 & 0.63 & - \\
\hline
\end{tabular}

chloride, and $0.02 \%$ sodium azide) was prepared and stored in a refrigerator at $4^{\circ} \mathrm{C}$.

The in vitro starch digestion test: Each sample $(50 \mathrm{mg})$ was suspended in a $50 \mathrm{ml}$ centrifuge tube containing $2 \mathrm{ml}$ deionized water, and then mixed well. Then, $8.0 \mathrm{ml}$ of enzyme solution $\left(37^{\circ} \mathrm{C}\right)$ was added to the tube, followed by incubation in a water bath at $37^{\circ} \mathrm{C}$ with shaking, at a stirring speed of $300 \mathrm{rpm}$. After the time periods of $0,10,20,60,120$, and $180 \mathrm{~min}$, the tube was shaken and $0.1 \mathrm{ml}$ aliquot was quickly taken and transferred to a $1.5 \mathrm{ml}$ centrifuge tube containing $0.9 \mathrm{ml}$ absolute ethanol to deactivate the enzymes. The tube was then returned for further time course digestion.

Starch digestibility was calculated using the GOPOD method by determining the glucose content. Based on the hydrolysis rate, starch was defined as rapidly digestible starch (RDS), slowly digestible starch (SDS), and resistant starch (RS).

\section{In vitro Digestion of Phenolic Compounds Extraction of Phenolic Compounds}

The extraction of polyphenolic compounds was performed according to the protocol of Horax et al. (9) with modifications. A total of $10 \mathrm{ml}$ of a methanol solution was added to $1 \mathrm{~g}$ of each sample and stirred for $2 \mathrm{~h}$ at $200 \mathrm{rpm}$, then treated for $15 \mathrm{~min}$ in an ultrasonic bath and finally centrifuged for $10 \mathrm{~min}$ at 6,000 $\mathrm{rpm}$. The pellet obtained was subjected to a second extraction and resuspended in $10 \mathrm{ml}$ of methanol solution and the second extraction was performed as described before.

\section{In vitro Digestion}

A static model that simulated gastrointestinal digestion was developed, following the method described by Minekus et al. (10). The detailed composition of simulated salivary fluid (SSF), simulated gastric fluid (SGF), and simulated intestinal fluid (SIF) is given in Table 1, and they were prepared from stock solutions fresh daily and kept at $37^{\circ} \mathrm{C}$ before use.

\section{In vitro Simulation of Saliva Digestion (SD)}

A total of $4 \mathrm{ml} \mathrm{SSF}$ was added to a $5.0 \mathrm{~g}$ barley powder sample and mixed well. Then, $15 \mathrm{mg} \alpha$-amylase, $25 \mu \mathrm{L}$ of $\mathrm{CaCl}_{2}$ solution, and $975 \mu \mathrm{L}$ water was added and shaken at $37^{\circ} \mathrm{C}$ for 2 min away from light.

\section{In vitro Simulation of Gastric Digestion (GD)}

A total of $160 \mathrm{mg}$ pepsin $(250 \mathrm{U} / \mathrm{mg}$ ) was added to $8.0 \mathrm{ml} \mathrm{SGF}$, and it is added to saliva digestive products. Then, $5 \mu \mathrm{L} \mathrm{CaCl}_{2}$ solution and $1990 \mu \mathrm{L}$ water were added. Thew $\mathrm{pH}$ was adjusted to 3 with $\mathrm{HCl}$, mixed well, and shaken away from light for $2 \mathrm{~h}$.

\section{In vitro Simulation of Intestinal Digestion (ID)}

About $144 \mathrm{mg}$ bile salt was added to $16.0 \mathrm{ml}$ SIF and stirred at $37^{\circ} \mathrm{C}$ for $20-30 \mathrm{~min}$. Then, $535 \mathrm{mg}$ trypsinase and $40 \mu \mathrm{L}$ $\mathrm{CaCl}_{2}$ solution were added to the gastric digestible products. The $\mathrm{pH}$ was adjusted to 7 with $\mathrm{NaOH}$ solution. After simulation, the samples were frozen at $-20^{\circ} \mathrm{C}$, lyophilized, and submitted to extraction as described above (Section Extraction of Phenolic Compounds).

\section{Determination of Phenolic Composition}

The individual phenolic compounds in the above extracts were quantified using a Shimazu LC-20AD HPLC system. A ZORBAX SB-Aq column $(5 \mathrm{~m}, 4.6 \mathrm{~mm} \times 250 \mathrm{~mm}$ ID, Agilent $)$ was used at a column temperature of $30^{\circ} \mathrm{C}$. The mobile phase consisted of a $0.1 \%$ aqueous solution of formic acid (solution A) and acetonitrile (solution $\mathrm{B}$ ) with the following gradient program: 0-10 min, solution B 3-3\%; 10-20 min, solution B 3-80\%; 20$30 \mathrm{~min}$, solution B $80-3 \%$; 30-35 min, solution B 3-3\%. Other chromatographic conditions included a constant flow rate of 0.8 $\mathrm{ml} / \mathrm{min}$, an injection volume of $20 \mu \mathrm{L}$, a run time of $35 \mathrm{~min}$, and a detection wavelength of 254 and $320 \mathrm{~nm}$. Prior to analysis, all samples were filtered through a $0.25-1 \mathrm{~m}$ membrane filter. The identification of each peak was based on the retention time and the chromatography of authentic standards. The concentrations of each compound were calculated according to a standard curve, and the results were expressed as $\mu \mathrm{g} / \mathrm{g} \mathrm{DW}$ of barley powder.

\section{Determination of Antioxidant Activity} Determination of DPPH Radical Scavenging Activity The method for determination of DPPH radical scavenging ability is based on measurement of the loss of DPPH radical color at $517 \mathrm{~nm}$ after reaction with sample extract and was performed as described by Brand-Williams et al. (11). Sample extracts (2 ml) were mixed with $2 \mathrm{ml}$ of DPPH radical solution, incubating for $30 \mathrm{~min}$ in the dark and measuring absorbance at $517 \mathrm{~nm}$. Sample extracts and anhydrous ethanol were used as a control group. Anhydrous ethanol and DPPH radical solution were used as a blank group. Results were expressed as the percentage of free radical scavenging.

\section{Determination of ABTS Radical Cation Scavenging Activity}

2, 2' -azino-BIS (3-ethylbenzothiazoline-6-sulfonic acid) (ABTS) radical cation scavenging capacity was measured using the modified method described by Sun et al. (12). Diluted the absorbance of ABTS radical cation solution to $0.70 \pm 0.02$ at $734 \mathrm{~nm}$. Extracts $(0.1 \mathrm{ml})$ were mixed with $2 \mathrm{ml} \mathrm{ABTS}$ radical cation, incubating 2-6 min, and measuring the absorbance at $734 \mathrm{~nm}$. Sample extracts and anhydrous ethanol were used as a control group. Anhydrous ethanol and ABTS radical cation were used as the blank group. Results were expressed as the percentage of free radical scavenging. 
TABLE 2 | Main nutritional and function component of BP, EBP, and FBP.

\begin{tabular}{lcccc}
\hline & Free phenol (mg/g) & $\boldsymbol{\beta}$-glucan (\%) & Protein (\%) & Fat (\%) \\
\hline BP & $25.63 \pm 1.15^{\mathrm{b}}$ & $3.83 \pm 0.68^{\mathrm{b}}$ & $13.99 \pm 0.32^{\mathrm{a}}$ & $2.61 \pm 0.21^{\mathrm{a}}$ \\
EBP & $14.78 \pm 0.52^{\mathrm{c}}$ & $3.52 \pm 0.17^{\mathrm{b}}$ & $13.50 \pm 1.09^{\mathrm{a}}$ & $1.07 \pm 0.21^{\mathrm{b}}$ \\
FBP & $34.72 \pm 0.61^{\mathrm{a}}$ & $11.97 \pm 1.42^{\mathrm{a}}$ & $14.67 \pm 0.41^{\mathrm{a}}$ & $0.76 \pm 0.21^{\mathrm{C}}$ \\
\hline
\end{tabular}

${ }^{a, b, c}$ Represents the highest figure in the data.

\section{Determination of Ferric Reducing Antioxidant Power-FRAP Method}

Ferric Reducing Antioxidant Power (FRAP) assay was performed according to a modified method reported by Benzie and Strain (13). Fresh FRAP working reagent was prepared by mixing $25 \mathrm{ml} 300 \mathrm{mM}$ acetate buffer, $2.5 \mathrm{ml}$ TPTZ solution, and $2.5 \mathrm{ml}$ of $20 \mathrm{mM} \mathrm{FeCl}_{3} \bullet 6 \mathrm{H}_{2} \mathrm{O}$ solution. $\mathrm{FeSO}_{4}$ solution was used as the standard solution. A total of $180 \mu \mathrm{L}$ FRAP solution was mixed with the standard solution in different concentrations and sample extracts, respectively. After incubation at $37^{\circ} \mathrm{C}$ for $3-5 \mathrm{~min}$, the absorbance was detected at $593 \mathrm{~nm}$.

\section{Statistical Analysis}

Each experiment was carried out in triplicate. Experimental design and data analysis were performed with IBM SPSS statistical software. Data were analyzed by ANOVA and expressed as mean \pm SD. $P<0.05$ was considered to be statistically significant.

\section{RESULTS AND DISCUSSION}

\section{Nutritional Components Analysis The Content of Free Phenol, $\beta$-Glucan, Protein, and Fat}

To evaluate the effects of extrusion and fermentation of barley powder, changes in main nutrients and amino acid contents were determined, as shown in Table 2. Compared with BP, the content of free phenol, $\beta$-glucan, and fat in EBP were all decreased by $42.33,8.09$, and 59\%, respectively. The content of free phenol and $\beta$-glucan in FBP was increased by 35.47 and $212.53 \%$, the content of fat in FBP was decreased by $70.88 \%$. The phenol and $\beta$-glucan content of FBP was significantly higher than that of BP and EBP, whereas the content of fat was lower than that in EBP, so FBP has greater significance in a healthy diet. The decrease of fat content and increase of $\beta$-glucan content in cereal can reduce its GI (glycemic index), which can be used in healthy food to reduce cholesterol, blood sugar, and blood fat of the human body.

The phenolic compounds are decomposed by high temperatures and the complex polyphenols are decomposed into other phenolic or non-phenolic compounds during extrusion, therefore, there is a loss of free phenol content. It is reported that there is a significant loss of total phenolics during the extrusion of oat cereals (14). These reports corroborate well with the findings of the present study. The increase of free phenol content after fermentation was mainly due to the acid hydrolysis produced by Lactobacillus fermentation that led to the release of the bound compound into a free state. Similarly, it found that the lactic acid bacteria fermentation increased the contents of the free, soluble conjugate, and total phenolics by 90.7, 17.2, and $37.1 \%$ respectively (15). Mao et al. (16) found that the total phenol content was increased significantly after fermentation, which was $39.10 \%$ higher than the raw wheat bran.

Tosh et al. (17) found that the depolymerization of the cell wall caused by pressure during the extrusion process leads to the loss of integrity, resulting in a decrease in the content of $\beta$-glucan in cereals. Similarly, it has been reported that it exhibited a significant decrease of $8 \%$ in $\beta$-glucan content when the extrusion temperature was constant at $150^{\circ} \mathrm{C}$, and when extrusion was carried out at $170^{\circ} \mathrm{C}, \beta$-glucan content lowered by $10 \%$ (18). The apparent increase in soluble $\beta$-glucan observed after fermentation might be due to enhanced activity of enzymes like $\beta$-glucanases and carboxypeptidases which cause degradation of total and insoluble $\beta$-glucan content into soluble $\beta$-glucan (4).

The decrease of the fat content of EBP might be due to the formation of lipid complexes under high temperatures and pressures. Hagenimana et al. (19) reported that decreases in the fat, protein, and reducing sugar content occurred through the many chemical and structural transformations such as starch gelatinization, protein denaturation, and complex formation between amylose and lipids during the extrusion process. Similarly, the fat content of white and red Ginseng samples significantly decreased from 1.29 to $0.23 \%$ after extrusion (20). The apparent decrease of fat content in FBP may be due to the degradation of lipids by lipase during fermentation, which is in agreement with what has been reported by Al-Ansi et al. (21). Besides, it is reported that the endo amylase played a vital role in starch hydrolysis during the fermentation process (22). Similarly, Chai et al. (23) found that the fat content of the Rambutan seed reduced by $22 \%$ whereas its free fatty acid content increased by 4.3 folds after 10 days of fermentation.

\section{The Content of Amino Acids}

As shown in Table 3, the most abundant amino acids in barley are glutamine, valine, leucine, phenylalanine, and proline. The contents of most amino acids decreased after extrusions, such as glutamic acid, leucine, and arginine, which may be due to the mutual conversion and decomposition of amino acids into small molecules of ammonia under the influence of high temperature and high pressure during extrusion. Similarly, the methionine and cysteine content of peas decreased after extrusion treatment (24).

The proportion of essential amino acids in FBP had increased, such as glutamic acid, glycine, alanine, and methionine. It may be due to the mutual conversion of amino acids during the fermentation of Lactobacillus plantarum. LAB fermentation can activate endogenous protease activity of barley powder by decreasing $\mathrm{pH}$ (25), thereby hydrolyzing protein and increasing free amino acid content. Additionally, proteases produced by microorganisms during fermentation could also hydrolyze the protein of wheat bran (26). Similarly, $\mathrm{Hu}$ et al. (5) found that the proportion of essential amino acids increased after fermentation, such as threonine, valine, and isoleucine Dallagnol. Mao et al. (16) found that methionine and cysteine of wheat bran were 
TABLE 3 | Free amino acids content (\%) of BP, EBP, and FBP.

\begin{tabular}{lccc}
\hline & BP & EBP & FBP \\
\hline Aspartic acid & $1.10 \pm 0.03^{\mathrm{a}}$ & $0.92 \pm 0.05^{\mathrm{b}}$ & $1.05 \pm 0.03^{\mathrm{a}}$ \\
Threonine & $0.66 \pm 0.02^{\mathrm{a}}$ & $0.58 \pm 0.02^{\mathrm{b}}$ & $0.68 \pm 0.01^{\mathrm{a}}$ \\
Serine & $0.86 \pm 0.01^{\mathrm{a}}$ & $0.79 \pm 0.07^{\mathrm{b}}$ & $0.90 \pm 0.01^{\mathrm{a}}$ \\
Glutamine & $5.40 \pm 0.13^{\mathrm{b}}$ & $4.89 \pm 0.15^{\mathrm{c}}$ & $5.56 \pm 0.21^{\mathrm{a}}$ \\
Glycine & $0.78 \pm 0.02^{\mathrm{b}}$ & $0.66 \pm 0.01^{\mathrm{c}}$ & $0.95 \pm 0.03^{\mathrm{a}}$ \\
Alanine & $0.84 \pm 0.03^{\mathrm{b}}$ & $0.71 \pm 0.03^{\mathrm{c}}$ & $0.91 \pm 0.06^{\mathrm{a}}$ \\
Cysteine & $0.29 \pm 0.01^{\mathrm{c}}$ & $0.44 \pm 0.01^{\mathrm{a}}$ & $0.38 \pm 0.03^{\mathrm{b}}$ \\
Valine & $1.29 \pm 0.08^{\mathrm{a}}$ & $1.06 \pm 0.04^{\mathrm{b}}$ & $1.22 \pm 0.05^{\mathrm{a}}$ \\
Methionine & $0.24 \pm 0.01^{\mathrm{b}}$ & $0.23 \pm 0.01^{\mathrm{b}}$ & $0.27 \pm 0.02^{\mathrm{a}}$ \\
Isoleucine & $0.76 \pm 0.04^{\mathrm{a}}$ & $0.64 \pm 0.01^{\mathrm{b}}$ & $0.76 \pm 0.03^{\mathrm{a}}$ \\
Leucine & $1.57 \pm 0.02^{\mathrm{a}}$ & $1.28 \pm 0.05^{\mathrm{b}}$ & $1.55 \pm 0.08^{\mathrm{a}}$ \\
Tyrosine & $0.97 \pm 0.03^{\mathrm{a}}$ & $0.88 \pm 0.13^{\mathrm{b}}$ & $1.01 \pm 0.11^{\mathrm{a}}$ \\
Phenylalanine & $1.37 \pm 0.17^{\mathrm{a}}$ & $1.26 \pm 0.13^{\mathrm{b}}$ & $1.38 \pm 0.09^{\mathrm{a}}$ \\
Lysine & $0.68 \pm 0.01^{\mathrm{a}}$ & $0.55 \pm 0.01^{\mathrm{b}}$ & $0.67 \pm 0.03^{\mathrm{a}}$ \\
Hlstidine & $0.42 \pm 0.03^{\mathrm{b}}$ & $0.36 \pm 0.01^{\mathrm{b}}$ & $0.84 \pm 0.02^{\mathrm{a}}$ \\
Argnine & $0.94 \pm 0.03^{\mathrm{a}}$ & $0.79 \pm 0.04^{\mathrm{b}}$ & $0.94 \pm 0.03^{\mathrm{a}}$ \\
Proline & $2.38 \pm 0.12^{\mathrm{b}}$ & $2.15 \pm 0.05^{\mathrm{c}}$ & $2.52 \pm 0.10^{\mathrm{a}}$ \\
\hline
\end{tabular}

${ }^{a, b, c}$ Represents the highest figure in the data.

TABLE 4 | Color of BP, EBP, and FBP.

\begin{tabular}{lccc}
\hline & \multicolumn{1}{c}{$\boldsymbol{L}^{*}$} & $\boldsymbol{a}^{*}$ & $\boldsymbol{b}^{*}$ \\
\hline BP & $92.07 \pm 0.02^{\mathrm{a}}$ & $1.26 \pm 0.01^{\mathrm{c}}$ & $5.48 \pm 0.04^{\mathrm{b}}$ \\
EBP & $88.28 \pm 0.01^{\mathrm{b}}$ & $1.76 \pm 0.03^{\mathrm{a}}$ & $9.53 \pm 0.01^{\mathrm{a}}$ \\
FBP & $86.32 \pm 0.02^{\mathrm{c}}$ & $1.39 \pm 0.02^{\mathrm{b}}$ & $4.15 \pm 0.05^{\mathrm{c}}$
\end{tabular}

a,b,c Represents the highest figure in the data.

$L^{*}$ represents the lightness, 0-100 represents dark to light, $a^{\star}$ represents the degree of the red-green and $b^{*}$ represents the degree of the yellow-blue.

increased by 315 and 33\%, respectively, after fermentation, the contents of tyrosine, phenylalanine, isoleucine, Val, and other essential amino acids were also significantly increased.

\section{Effects of Extrusion and Fermentation on Physicochemical Properties Color}

Color is an important sensory quality of barley powder. The brightness $\left(L^{*}\right)$, red-green $\left(a^{*}\right)$, and yellow-blue $\left(b^{*}\right)$ of the samples are shown in Table 4 . In general, the $L^{*}$ value of EBP decreases, while $a^{*}$ and $b^{*}$ values increase, $L^{*}$ and $b^{*}$ values of FBP decrease, while $a^{*}$ value increases. The BP was brighter than the EBP, which was brighter than the FBP. The EBP was greener than the FBP, which was greener than the BP. The EBP was bluer than the BP, which was bluer than the FBP.

The observed change in color of EBP may be attributed to the gelatinization caused by high temperature and high-pressure during extrusion. Reduced sugars and proteins (amino acids) in grain can react under high processing temperatures to promote non-enzymatic browning (Maillard reaction), which results in the darkening of the EBP (27). Similarly, previous researchers have observed that extrusion of the whey protein concentrate and corn starch resulted in higher color differences with the
TABLE 5 | WSI and WAI of BP, EBP, and FBP.

\begin{tabular}{lcc}
\hline & WSI (\%) & WAI (\%) \\
\hline BP & $9.73 \pm 0.23^{\mathrm{b}}$ & $190.13 \pm 8.89^{\mathrm{c}}$ \\
EBP & $10.66 \pm 0.50^{\mathrm{a}}$ & $462.93 \pm 3.80^{\mathrm{b}}$ \\
FBP & $18.00 \pm 0.40^{\mathrm{c}}$ & $696.80 \pm 4.50^{\mathrm{a}}$ \\
\hline
\end{tabular}

${ }_{a, b, c}$ Represents the highest figure in the data.

increase in the amylose content (28). The color change of FBP is also related to the browning reaction where a fluctuation in $L^{*}$ values and an increase in $a^{*}$ values indicate more browning (29). Similarly, previous researchers have observed that there were significant differences in $a^{*}$ and $b^{*}$ values obtained between unfermented and fermented seeds of rambutan (30).

\section{WSI and WAI}

The water solubility index (WSI) of barley powder is related to the degree of starch degradation. As shown in Table 5, the WSI was significantly increased from 9.73 (BP) to $10.66 \%$ (EBP) after the extrusion of barley powder. It was also found that the WSI of pea flour significantly increased after extrusion from 11.70 to $54.9 \%$ (31). It has been reported that the crystalline structure was disrupted, and starch was gelatinized during extrusion so that the amylose leached out to cause the increase in the WSI (32). The WSI of FBP was found to be $18.00 \%$, which was remarkably higher than the BP and EBP. It has been reported that molecular components of starch are degraded during fermentation which results in increased soluble components. Similarly, the gel forming capacity of the fermented rice black gram mix flour was significantly higher than the extrudate products (3).

The WAI reflects the water absorption capacity of barley powder and is significantly dependent on molecular interactions in the crystalline and amorphous regions of the starch granule (33). As shown in Table 2, the WAI of EBP was $462.93 \%$ higher than BP. It was also found that the WAI of rice starch significantly increased after extrusion from 136 to $246-412 \%$ at different moisture contents (32).

\section{Pasting Properties}

Pasting properties are very important in the process of choosing new food manufacturing additives, such as thickeners, emulsifiers, binders, or other components related to paste viscosity (34). Therefore, the result may be used for the indirect estimation of the intensity of the extrusion and fermentation treatment of barley powder. As shown in Table 6, the PV, TV, FV, SB, PT, and PTT of BP are higher than EBP and EBP, which indicated that the $\mathrm{BP}$ showed more stable viscosity properties during measurements. The starch pasting levels of EBP and FBP were increased, which could effectively optimize the taste of barley products, and further facilitate the development of barley edible products.

The peak viscosity of samples is influenced by amylose content, starch leaching, as well as the content of other components, such as proteins, lipids, and fibers (35). The decrease in PV of EBP may be attributable to starch pasting, protein denaturation, and interactions between starch and protein (36). Additionally, the reduced paste viscosity could be 
TABLE 6 | Pasting properties of BP, EBP, and FBP.

\begin{tabular}{|c|c|c|c|c|c|c|c|}
\hline & PV (cp) & TV (cp) & BD (cp) & FV (cp) & SB (cp) & PT (min) & PTT $\left({ }^{\circ} \mathrm{C}\right)$ \\
\hline $\mathrm{BP}$ & $4,731.00 \pm 94.62^{a}$ & $3,314.00 \pm 36.04^{a}$ & $1,417.00 \pm 41.58^{b}$ & $5,224.33 \pm 88.24^{a}$ & $1,910.33 \pm 6.51^{a}$ & $6.73 \pm 0.07^{a}$ & $72.02 \pm 0.42^{a}$ \\
\hline EBP & $2,189.67 \pm 75.55^{c}$ & $664.67 \pm 41.10^{c}$ & $1,786.00 \pm 99.01^{b}$ & $1,305.00 \pm 73.91^{c}$ & $677.00 \pm 45.97^{\mathrm{c}}$ & $5.33 \pm 0.11^{b}$ & $66.18 \pm 7.20^{\mathrm{a}}$ \\
\hline FBP & $3,230.33 \pm 75.93^{b}$ & $1,005.00 \pm 16.46^{b}$ & $2,225.33 \pm 116.09^{a}$ & $1,822.00 \pm 38.43^{b}$ & $817.00 \pm 35.04^{b}$ & $1.09 \pm 0.03^{c}$ & $52.60 \pm 2.08^{b}$ \\
\hline
\end{tabular}

${ }^{a, b, c}$ Represents the highest figure in the data.

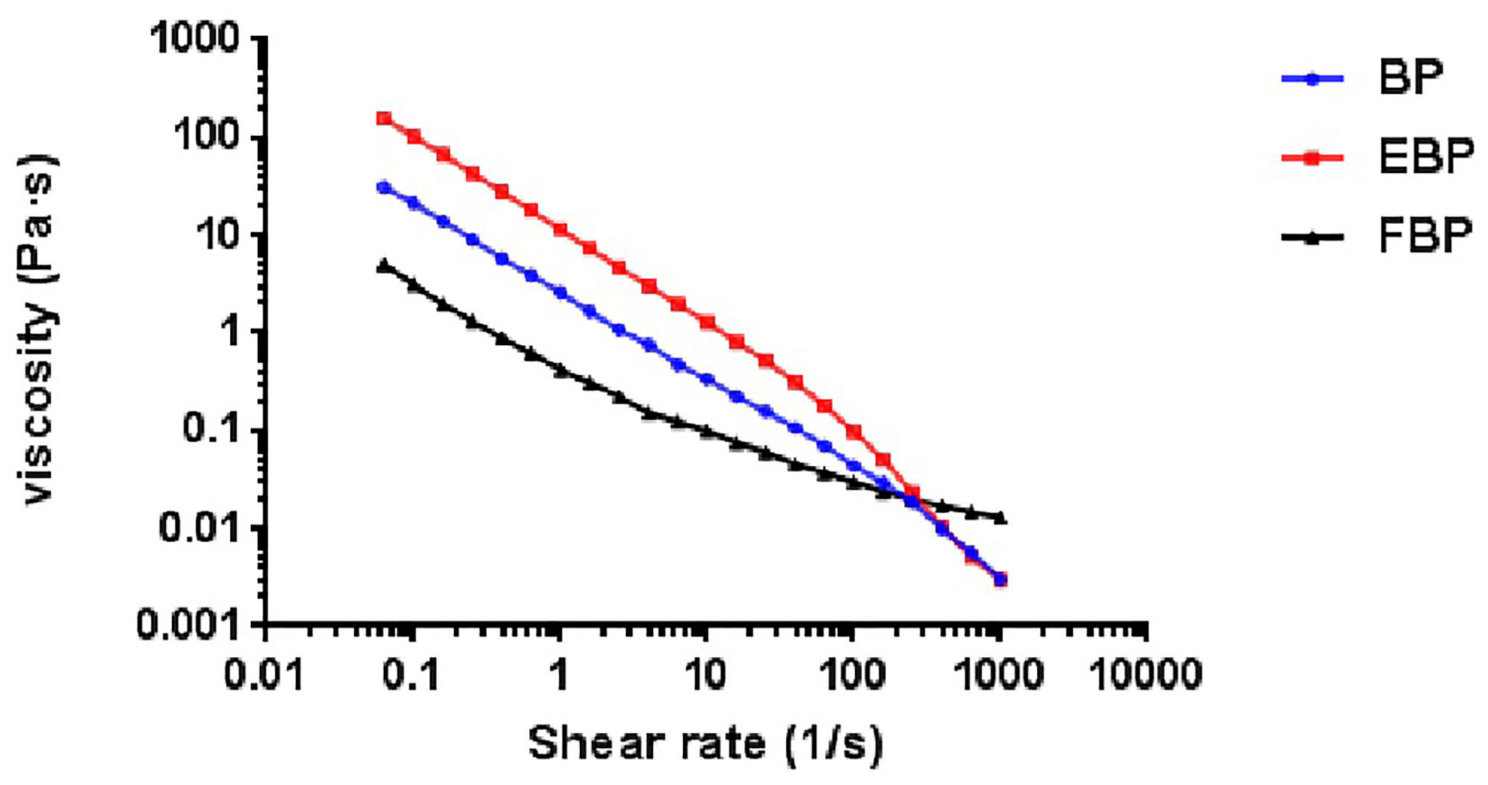

FIGURE 1 | The static viscoelasticity of BP, EBP, and FBP.

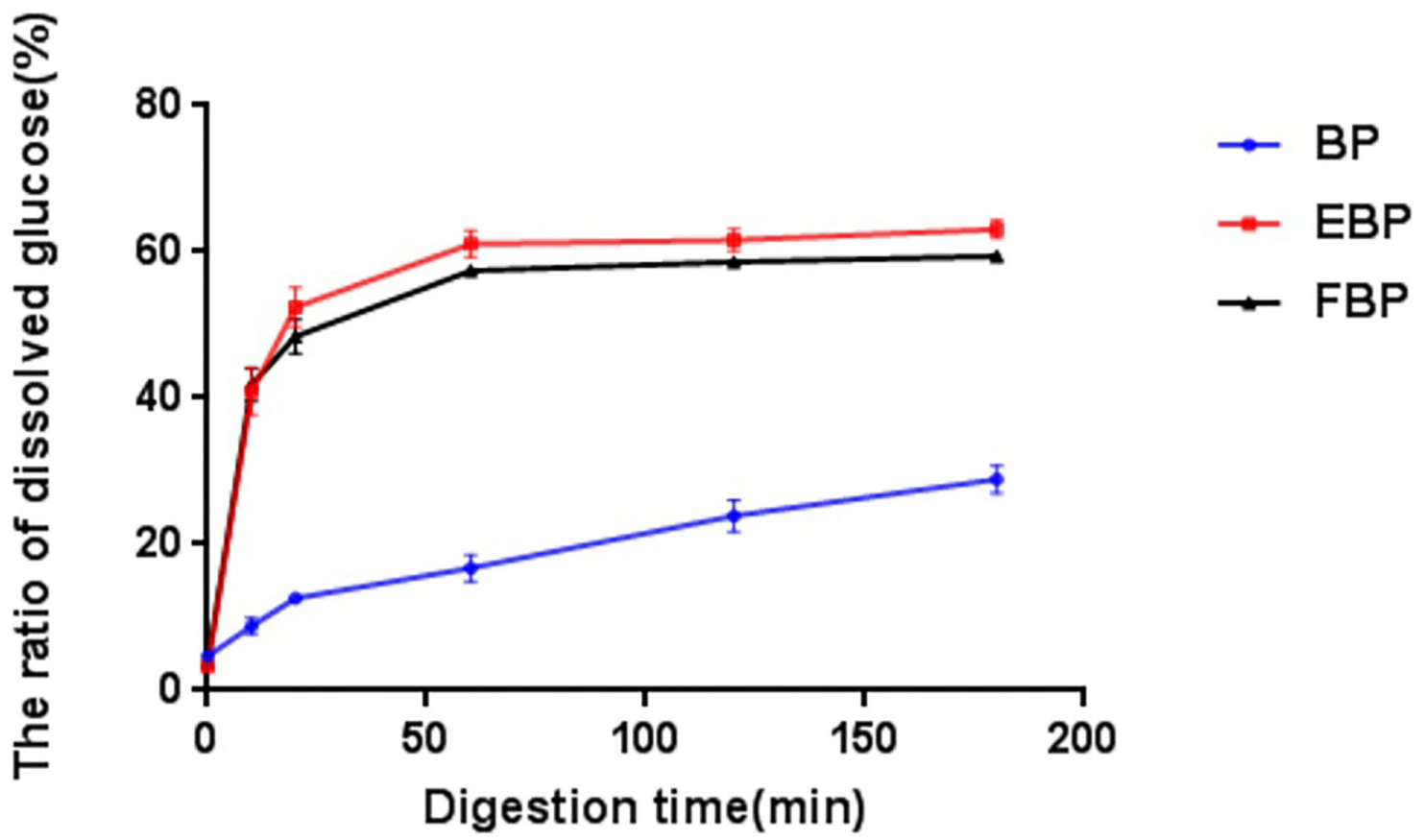

FIGURE 2 | The starch decomposition rate during digestion of BP, EBP, and FBP. 
attributed to the formation of compact starch granules during high temperature treatment, which had higher resistance to heat and shear during pasting. The decline in PV of FBP might be caused by amylopectin degradation, disruption of granular structures, and disordering of hierarchical structures of starch (8).

Trough viscosity (TV) indicates the sensitivity of starch granules to shearing. During the $95^{\circ} \mathrm{C}$ period, swollen granules disintegrated due to the shearing of the paddle and rotating bowl, resulting in a decrease in viscosity known as viscosity breakdown. Final viscosity (FV) indicates a retrogradation tendency of the soluble amylose after cooling, or the ability of the starch paste to form a gel (35). Breakdown (BD) is a characteristic feature of shear resistance and heat resistance of starch hot paste. Setback (SB) reflects the stability and aging trend of starch cold paste, a lower setback value indicates higher stability. The content and structure of Amylose and amylopectin in barley flour can affect the pasting time (PT) and pasting temperature (PTT), higher amylose content, and the longer branched chain of amylopectin cause higher heat to dissolve the crystal and higher PTT.

The decrease in TV, FV, BD, and SB of EBP may be attributable to the speed and temperature of the high extruder screw. Similar observations were reported by Siddiq et al. (37), and Mitrus et al. (38). The reduction in TV, FV, BD, and SB of FBP may be attributable to the higher $\alpha$-amylase activity; the starch grains tend to lose resistance to swelling, and thus, the viscosity declines (39). Similar observations were reported that the fermentation significantly decreased the pasting properties by Al-Ansi et al. (40) and Zhao et al. (41).

\section{Static Viscoelasticity}

As shown in Figure 1, the static rheological properties of BP, EBP, and FBP show the same trend of viscosity change, and the viscosity decreases with the increase of shear rate which might be due to the increasing external force with the increase of shear rate, and the destruction of the hydration structure between polysaccharide molecules and water molecules, leading to the decrease of viscosity. The initial viscosity of EBP is higher than that of BP, and that of FBP is lower than that of BP. The decrease of viscosity is beneficial to improve the palatability of popular products and further promote the development and utilization of barley in the food industry.

\section{In vitro Digestion of Starch Starch Decomposition Rate}

As can be seen from Figure 2, during the digestion of the sample in vitro, the hydrolysis rate of starch increased rapidly in the first $60 \mathrm{~min}$, especially in the first $20 \mathrm{~min}$. The hydrolysis rate of starch from high to low was EBP, FBP, and BP at $180 \mathrm{~min}$. The results showed that the digestibility of barley powder could be improved by extrusion and fermentation, and it could be rapidly decomposed into reducing sugars in the human body for absorption and utilization. Similar observations were reported by de la Rosa-Millán et al. (42).

\section{Contents of TS, RDS, SDS, and RS}

The contents of RDS, SDS, and RS in the BP, EBP, and FBP are shown in Table 7. Compared to the BP, EBP, and FBP had less
TABLE 7 | Content of TS, RDS, SDS and RS of BP, EBP, and FBP (\%).

\begin{tabular}{lccc}
\hline & RDS & SDS & RS \\
\hline BP & $14.92 \pm 1.49^{\mathrm{b}}$ & $18.58 \pm 0.88^{\mathrm{a}}$ & $68.66 \pm 1.69^{\mathrm{a}}$ \\
EBP & $73.77 \pm 2.01^{\mathrm{a}}$ & $11.77 \pm 0.76^{\mathrm{b}}$ & $14.46 \pm 1.25^{\mathrm{c}}$ \\
FBP & $64.30 \pm 1.16^{\mathrm{a}}$ & $6.59 \pm 0.52^{\mathrm{b}}$ & $29.11 \pm 1.16^{\mathrm{b}}$
\end{tabular}

${ }_{a, b, c}$ Represents the highest figure in the data.

SDS and RS, but more RDS, which indicated that both extrusion and fermentation could accelerate the digestion of the starch by transforming SDS and RS into RDS, significantly improving the digestibility of barley powder, and the effect of EBP was more obvious than that of FBP.

Rapidly digestible starch can be quickly digested by the human body, and its content is one of the indicators of digestible foods that can predict elevated glycaemic index. The increase in RDS of EBP could be due to the direct effect of the extrusion treatment on starch granules as BP contains little or no detectable $\alpha$ amylose inhibitors (43). SDS results in the slow release of glucose into the blood; such property is advantageous for human health as it prevents diabetes and obesity. RS is known as a type of dietary fiber that cannot be digested in the small intestine. The significant increase in RDS of EBP, with a corresponding decrease in the RS, is probably due to the extrusion treatment decreasing starch crystallinity and increasing enzyme availability results in a decrease in RS content. A similar result has been reported by Chen et al. (44).

There was also a significant increase in the RDS content after fermentation from 14.92 to $64.30 \%$ and the RS content decreased from 68.66 to $29.11 \%$. Golden found that the significant increase in RDS of FBP, with a corresponding decrease in the RS might be due to the disruption of the ordered structure of starch chains by actions of microbial organisms during fermentation, thereby increasing the accessibility of starch granules to the digestive enzymes (45). A similar result has been reported for the sorghum flour and cassava flour by Inglett et al. (46) and Elkhalifa et al. (47).

\section{In vitro Digestion of Polyphenols Polyphenols Component}

The 7 phenolic compounds from samples were analyzed and are presented in Table 8. According to the HPLC analyses, the total content of each phenolic compound in abstracts from barley powder significantly increased during fermentation while decreased during extrusion. Quantitative results indicated that cumaric acid was the most abundant compound in barley, followed by 2-hydroxybenzoic acid, chlorogenic acid, and 3, 4dihydroxybenzoic acid, additionally, after in vitro simulation of saliva, gastric, and intestinal digestion.

Compared to the BP, the content of ferulic acid, 2hydroxybenzoic acid, and caffeic acid were significantly decreased in EBP. Extrusion could inevitably lead to a decrease of free phenolic acids because of decomposition caused by the high temperature. A similar result has been reported by Zeng et al. (48) for the extruded brown rice and extruded wheat. The contents of chlorogenic acid, p-coumaric acid, and ferulic 
TABLE 8 | The content of phenolic compounds before and after digestion in vitro.

\begin{tabular}{|c|c|c|c|c|c|c|c|c|}
\hline & $\begin{array}{c}\text { 3, 4- } \\
\text { dihydroxybenzoic } \\
\text { acid }\end{array}$ & $\begin{array}{l}\text { Chlorogenic acid } \\
\text { c }\end{array}$ & Caffeic acid & p-coumaric acid & Ferulic acid & $\begin{array}{l}2- \\
\text { hydroxybenzoic } \\
\text { acid }\end{array}$ & Vanillic acid & Total \\
\hline BP (Before digestion) & $12.24 \pm 0.56^{c}$ & $14.67 \pm 0.27^{d}$ & $7.90 \pm 0.28^{b}$ & $154.72 \pm 2.37^{d}$ & $12.17 \pm 0.22^{b}$ & $20.35 \pm 0.38^{b}$ & $6.81 \pm 0.17^{b}$ & $228.86 \pm 4.86^{d}$ \\
\hline EBP (Before digestion) & $9.18 \pm 0.83^{d}$ & $11.68 \pm 0.25^{\mathrm{e}}$ & $3.30 \pm 0.26^{c}$ & $141.94 \pm 2.84^{d}$ & $3.87 \pm 0.69^{c}$ & $2.76 \pm 0.06^{c}$ & $3.85 \pm 0.37^{c}$ & $176.59 \pm 6.63^{\mathrm{e}}$ \\
\hline FBP (Before digestion) & $12.36 \pm 0.64^{c}$ & $17.34 \pm 0.65^{c}$ & $10.61 \pm 0.74^{a}$ & $214.91 \pm 3.59^{c}$ & $16.19 \pm 0.74^{a}$ & $25.81 \pm 1.36^{\mathrm{b}}$ & $7.22 \pm 0.82^{b}$ & $304.43 \pm 9.74^{c}$ \\
\hline BP (After digestion) & $15.58 \pm 0.74^{b}$ & $26.99 \pm 0.98^{b}$ & $8.46 \pm 0.50^{b}$ & $261.14 \pm 1.48^{\mathrm{b}}$ & $4.38 \pm 0.56^{c}$ & $40.36 \pm 1.74^{\mathrm{a}}$ & $9.63 \pm 1.48^{a}$ & $366.54 \pm 7.48^{b}$ \\
\hline EBP (After digestion) & $14.98 \pm 0.26^{b}$ & $22.02 \pm 0.42^{\mathrm{b}}$ & $5.79 \pm 0.37^{c}$ & $222.91 \pm 2.94^{c}$ & $8.53 \pm 0.85^{b}$ & $18.44 \pm 0.59^{b}$ & $9.01 \pm 0.94^{a}$ & $301.70 \pm 6.06^{c}$ \\
\hline FBP (After digestion) & $17.39 \pm 0.47^{a}$ & $44.70 \pm 2.20^{\mathrm{a}}$ & $11.65 \pm 0.99^{a}$ & $331.70 \pm 3.58^{a}$ & $18.32 \pm 0.59^{a}$ & $28.14 \pm 0.37^{b}$ & $10.80 \pm 0.42^{a}$ & $462.69 \pm 9.04^{a}$ \\
\hline
\end{tabular}

${ }^{a, b, c}$ Represents the highest figure in the data.

TABLE 9 | Antioxidant activity of BP, EBP, and FBP (\%).

\begin{tabular}{lccc}
\hline & $\begin{array}{c}\text { DPPH• } \\
\text { scavenging } \\
\text { activity }\end{array}$ & $\begin{array}{c}\text { ABTS }^{+} \\
\text {scavenging } \\
\text { activity }\end{array}$ & FRAP \\
\hline BP & $46.03 \pm 2.32^{\mathrm{b}}$ & $14.25 \pm 0.28^{\mathrm{b}}$ & $52.39 \pm 3.21^{\mathrm{b}}$ \\
EBP & $18.49 \pm 2.18^{\mathrm{c}}$ & $12.42 \pm 0.89^{\mathrm{c}}$ & $37.36 \pm 1.69^{\mathrm{c}}$ \\
FBP & $71.32 \pm 3.78^{\mathrm{a}}$ & $16.49 .99 \pm 0.26^{\mathrm{a}}$ & $112.36 \pm 5.60^{\mathrm{a}}$ \\
\hline
\end{tabular}

${ }_{a, b, c}$ Represents the highest figure in the data.

acid were dramatically increased in FBP. It was widely reported that phenolic acids in cereals were mainly in bound form and involved in linkages of ester, ether, or acetal bonds to cellulose, proteins, or lignin. These linkages break due to the enzymes produced during fermentation such as esterases and proteases. A similar result has been reported for the fermented rice bran (15).

\section{Antioxidant Activity}

As shown in Table 9, the DPPH•, ABTS radical cation, and FRAP of BP are higher than those of EBP and lower than those of FBP, indicating that the antioxidant capacity of barley powder was partially lost during the extrusion process and enhanced during the fermentation process. It was observed that there was a positive correlation between the total phenolic content and antioxidant activity.

It had been proven that fermentation could improve the antioxidant activity of barley powder, mainly due to the release of free bioactive compounds caused by biological acidification and microbial enzyme activity (49). A similar result has been reported by Mao et al. (16) for the wheat bran and Chu et al. (50) for the millet bran. Extrusion probably caused the breakdown of phenolic, while fermentation helped to dissolve the phenols as well as improve the extraction efficiency. The increased content of total phenolic contributed to the antioxidant activity and that was consistent with the previous report (51).

\section{CONCLUSION}

The contents of phenols, $\beta$-glucan, protein, and lipid decreased after extrusion. A variety of nutrients and the content of essential amino acids increased after fermentation. The antioxidant capacity of EBP was lower than that of BP, and that of FBP was higher than that of $\mathrm{BP}$, which was consistent with the change of phenolic content. Both Maillard reaction during extrusion, and enzymatic browning during fermentation of barley flour can lead to the darkening of the color, and can effectively optimize the palatability of the barley powder by reducing the viscosity. The RDS content of EBP and FBP were higher than that of $\mathrm{BP}$, which indicated that both extrusion and fermentation could improve the digestibility of barley. The results can be used in the application of fermentation and extrusion in the food industry, especially in the production of high digestibility food such as baby rice paste and feed.

\section{DATA AVAILABILITY STATEMENT}

The original contributions presented in the study are included in the article/supplementary material, further inquiries can be directed to the corresponding author.

\section{AUTHOR CONTRIBUTIONS}

XX designed the scheme and provided funding acquisition and project administration. JL wrote the main part of the manuscript and participated in the planning and execution of all the experiments. HX assisted in part of the experiment and analyzed it. WT helped with some of the experiments. YZ participated in the design of the experimental scheme. JZ was responsible for writing, reviewing editing, and supervision. All authors read and approved the final manuscript.

\section{FUNDING}

This work was supported by the Yangzhou key research and development project (modern agriculture) [YZ2020043]; Jiangsu Province agricultural independent innovation project [CX (20) 2036].

\section{ACKNOWLEDGMENTS}

Thanks to all authors for their contributions to the experiment. 


\section{REFERENCES}

1. Gangopadhyay N, Hossain MB, Rai DK, Brunton NP. A review of extraction and analysis of bioactives in oat and barley and scope for use of novel food processing technologies. Molecules. (2015) 20:10884909. doi: 10.3390/molecules200610884

2. Kariluoto S, Edelmann M, Nyström L, Sontag-Strohm T, Salovaara H, Kivelä $\mathrm{R}$, et al. In situ enrichment of folate by microorganisms in betaglucan rich oat and barley matrices. Int J Food Microbiol. (2014) 176:3848. doi: 10.1016/j.ijfoodmicro.2014.01.018

3. Rani P, Kumar A, Purohit S, Rao P. Impact of fermentation and extrusion processing on physicochemical, sensory and bioactive properties of riceblack gram mixed flour. LWT - Food Science and Technology. (2017) 89. doi: 10.1016/j.lwt.2017.10.050

4. Arora S, Jood S, Khetarpaul N, Goyal R. Effect of germination and fermentation on ph. Titratable acidity and chemical composition of pearl millet based food blends. Acta Alimentaria - ACTA ALIMENT. (2009) 38:10715. doi: 10.1556/AAlim.2008.0024

5. Hu Y, Piao C, Chen Y, Zhou Y, Wang D, Yu H, et al. Soybean residue (okara) fermentation with the yeast Kluyveromyces marxianus. Food Bioscience. (2019) 31:100439. doi: 10.1016/j.fbio.2019.100439

6. Morris CF, Jeffers HC, Engle DA. Effect of processing, formula and measurement variables on alkaline noodle color-toward an optimized laboratory system. Cereal Chem. (2000) 77:77-85. doi: 10.1094/CCHEM.2000.77.1.77

7. Wang H, Wu J, Luo S, Zou P, Guo B, Liu Y, et al. Improving instant properties of kudzu powder by extrusion treatment and its related mechanism. Food Hydrocoll. (2019) 101:105475. doi: 10.1016/j.foodhyd.2019.105475

8. Wang H, Xiao N, Ding J, Zhang Y, Liu X, Zhang H. Effect of germination temperature on hierarchical structures of starch from brown rice and their relation to pasting properties. Int J Biol Macromol. (2020) 147:96572. doi: 10.1016/j.ijbiomac.2019.10.063

9. Horax R, Hettiarachchy N, Islam S. Total phenolic contents and phenolic acid constituents in 4 varieties of bitter melons (Momordica charantia) and antioxidant activities of their extracts. J Food Sci. (2005) 70:C27580. doi: 10.1111/j.1365-2621.2005.tb07173.x

10. Minekus $M$, Alminger $M$, Alvito $P$, Ballance $S$, Bohn $T$, Bourlieu $\mathrm{C}$, et al. A standardised static in vitro digestion method suitable for food - an international consensus. Food Funct. (2014) 5:111324. doi: 10.1039/C3FO60702J

11. Brand-Williams W, Cuvelier ME, Berset C. Use of a free radical method to evaluate antioxidant activity. LWT - Food Science and Technology. (1995) 28:25-30. doi: 10.1016/S0023-6438(95)80008-5

12. Sun Y, Qin Y, Li H, Peng H, Chen H, Xie HR, et al. Rapid characterization of chemical constituents in Radix Tetrastigma, a functional herbal mixture, before and after metabolism and their antioxidant/antiproliferative activities. J Funct Foods. (2015) 18:300-18. doi: 10.1016/j.jff.2015.07.009

13. Benzie IF, Strain JJ. Ferric reducing/antioxidant power assay: direct measure of total antioxidant activity of biological fluids and modified version for simultaneous measurement of total antioxidant power and ascorbic acid concentration. Methods Enzymol. (1999) 299:15-27. doi: 10.1016/S0076-6879(99)99005-5

14. Viscidi K, Dougherty M, Briggs J, Camire M. Complex phenolic compounds reduce lipid oxidation in extruded oat cereals. LWT - Food Sci Technol. (2004) 37:789-96. doi: 10.1016/j.lwt.2004.03.005

15. Liu L, Zhang R, Deng Y, Zhang Y, Xiao J, Huang F, et al. Fermentation and complex enzyme hydrolysis enhance total phenolics and antioxidant activity of aqueous solution from rice bran pretreated by steaming with $\alpha$-amylase. Food Chem. (2017) 221:636-43. doi: 10.1016/j.foodchem.2016. 11.126

16. Mao M, Wang P, Shi K, Bie X, Zhao $\mathrm{H}$, Zhan $\mathrm{C}$, et al. Effect of solid state fermentation by Enterococcus faecalis M2 on antioxidant and nutritional properties of wheat bran. J Cereal Sci. (2020) 94:102997. doi: 10.1016/j.jcs.2020.102997

17. Tosh SM, Brummer Y, Miller SS, Regand A, Defelice C, Duss R, et al. Processing affects the physicochemical properties of beta-glucan in oat bran cereal. J Agric Food Chem. (2010) 58:7723-30. doi: 10.1021/jf904553u
18. Huth M, Dongowski G, Gebhardt E, Flamme W. Functional properties of dietary fibre enriched extrudates from barley. J Cereal Sci. (2000) 32:115-28. doi: $10.1006 /$ jcrs. 2000.0330

19. Hagenimana A, Ding X, Fang T. Evaluation of rice flour modified by extrusion cooking. J Cereal Sci. (2006) 43:38-46. doi: 10.1016/j.jcs.2005.09.003

20. Gui Y, Ryu GH. Effects of extrusion cooking on physicochemical properties of white and red ginseng (powder). J Ginseng Res. (2014) 38:14653. doi: 10.1016/j.jgr.2013.12.002

21. Al-Ansi W, Mahdi A, Al-Maqtari Q, Sajid B, Ahmed A, Karrar E, et al. The potential improvements of naked barley pretreatments on GABA, $\beta$-glucan, and antioxidant properties. LWT. (2020) 130:109698. doi: 10.1016/j.lwt.2020.109698

22. Kalita D, Sarma B, Srivastava B. Influence of germination conditions on malting potential of low and normal amylose paddy and changes in enzymatic activity and physico chemical properties. Food Chem. (2017) 220:67-75. doi: 10.1016/j.foodchem.2016.09.193

23. Chai KF, Adzahan NM, Karim R, Rukayadi Y, Ghazali HM. Fat properties and antinutrient content of rambutan (Nephelium lappaceum L.) seed during solid-state fermentation of rambutan fruit. Food Chem. (2019). 274:808-15. doi: 10.1016/j.foodchem.2018.09.065

24. Urbano, G., López-Jurado, M., Frejnagel, S., Gómez-Villalva, E., Porres, J. M., Frías, J., et al. (2005). Nutritional assessment of raw and germinated pea (Pisum sativum L.) protein and carbohydrate by in vitro and in vivo techniques. Nutrition 21, 230-239. doi: 10.1016/j.nut.2004.04.025

25. Dallagnol AM, Pescuma M, De Valdez GF, Rollán G. Fermentation of quinoa and wheat slurries by Lactobacillus plantarum CRL 778: proteolytic activity. Appl Microbiol Biotechnol. (2013) 97:3129-40. doi: 10.1007/s00253-012-4520-3

26. Capuani A, Behr J, Vogel RF. Influence of lactic acid bacteria on redox status and on proteolytic activity of buckwheat (Fagopyrum esculentum Moench) sourdoughs. Int J Food Microbiol. (2013) 165:148-55. doi: 10.1016/j.ijfoodmicro.2013.04.020

27. Nayak B, Berrios Jde J, Powers JR, Tang J. Effect of extrusion on the antioxidant capacity and color attributes of expanded extrudates prepared from purple potato and yellow pea flour mixes. J Food Sci. (2011) 76:C874883. doi: 10.1111/j.1750-3841.2011.02279.x

28. Matthey F, Hanna M. Physical and Functional Properties of Twin-screw Extruded Whey Protein Concentrate-Corn Starch Blends. LWT - Food Sci Technol. (1997) 30:359-66. doi: 10.1006/fstl.1996.0189

29. Hawlader MNA, Perera CO, Tian M. Properties of modified atmosphere heat pump dried foods. J Food Eng. (2006) 74:392-401. doi: 10.1016/j.jfoodeng.2005.03.028

30. Mehdizadeh S, Lasekan OO, Muhammad K, Baharin B. Variability in the fermentation index, polyphenols and amino acids of seeds of rambutan (Nephelium lappaceum L.) during fermentation. J Food Composit Analy. (2014) 37. doi: 10.1016/j.jfca.2014.06.017

31. Kristiawan M, Micard V, Maladira P, Alchamieh C, Maigret JE, Réguerre AL, et al. Multi-scale structural changes of starch and proteins during pea flour extrusion. Food Res Int. (2018) 108:203-15. doi: 10.1016/j.foodres.2018.03.027

32. Liu Y, Chen J, Luo S, Li C, Ye J, Liu C, et al. Physicochemical and structural properties of pregelatinized starch prepared by improved extrusion cooking technology. Carbohydr Polym. (2017) 175:265-72. doi: 10.1016/j.carbpol.2017.07.084

33. Chen J-Y, Liu J, Tang X, Shen X, Liu S. Correlations between the physical properties and chemical bonds of extruded corn starch enriched with whey protein concentrate. RSC Adv. (2017) 7:11979-86. doi: 10.1039/C6RA26764E

34. Natabirwa H, Muyonga JH, Nakimbugwe D, Lungaho M. Physico-chemical properties and extrusion behaviour of selected common bean varieties. J Sci Food Agric. (2018) 98:1492-501. doi: 10.1002/jsfa.8618

35. Lopes L, Batista K, Fernandes K, Santiago R. Functional, biochemical and pasting properties of extruded bean (Phaseolus vulgaris) cotyledons. Int J Food Sci Technol. (2012) 47. doi: 10.1111/j.1365-2621.2012.03042.x

36. Nkundabombi MG, Nakimbugwe D, Muyonga JH. Effect of processing methods on nutritional, sensory, and physicochemical characteristics of biofortified bean flour. Food Sci Nutr. (2016) 4:384-97. doi: 10.1002/fsn3.301

37. Siddiq M, Kelkar S, Harte JB, Dolan KD, Nyombaire G. Functional properties of flour from low-temperature extruded navy and pinto 
beans (Phaseolus vulgaris L.). LWT - Food Sci Technol. (2013) 50:2159. doi: 10.1016/j.lwt.2012.05.024

38. Mitrus M, Wójtowicz A, Kocira S, Kasprzycka A, Szparaga A, Oniszczuk $\mathrm{T}$, et al. Effect of extrusion-cooking conditions on the pasting properties of extruded white and red bean seeds. Int Agrophys. (2020). 34:2532. doi: $10.31545 /$ intagr/116388

39. Simsek S, Ohm JB, Lu H, Rugg M, Berzonsky W, Alamri MS, et al. Effect of pre-harvest sprouting on physicochemical properties of starch in wheat. Foods. (2014) 3:194-207. doi: 10.3390/foods3020194

40. Al-Ansi W, Sajid BM, Mahdi AA, Al-Maqtari QA, Al-Adeeb A, Ahmed A, et al. Molecular structure, morphological, and physicochemical properties of highlands barley starch as affected by natural fermentation. Food Chem. (2021) 356:129665. doi: 10.1016/j.foodchem.2021.129665

41. Zhao T, Li X, Zhu R, Ma Z, Liu L, Wang X, et al. Effect of natural fermentation on the structure and physicochemical properties of wheat starch. Carbohydr Polym. (2019) 218:163-9. doi: 10.1016/j.carbpol.2019.04.061

42. de la Rosa-Millán J, Heredia-Olea E, Perez-Carrillo E, GuajardoFlores D, Serna-Saldívar SR. Effect of decortication, germination and extrusion on physicochemical and in vitro protein and starch digestion characteristics of black beans (Phaseolus vulgaris L.). LWT. (2019) 102:330-337. doi: 10.1016/j.lwt.2018.12.039

43. Alonso R, Grant G, Dewey P, Marzo F. Nutritional assessment in vitro and in vivo of raw and extruded peas (Pisum sativum L.). J Agric Food Chem. (2000) 48:2286-90. doi: 10.1021/jf000095o

44. Chen Y, Ma Y, Dong L, Jia X, Liu L, Huang F, et al. Extrusion and fungal fermentation change the profile and antioxidant activity of free and bound phenolics in rice bran together with the phenolic bioaccessibility. LWT. (2019) 115:108461. doi: 10.1016/j.lwt.2019.108461

45. Odey G, Lee W. Evaluation of the quality characteristics of flour and pasta from fermented cassava roots. Int J Food Sci Technol. (2019) 55. doi: 10.1111/ijfs.14364

46. Inglett GE, Peterson S, Carriere C, Maneepun S. Rheological, textural, and sensory properties of Asian noodles containing an oat cereal hydrocolloid. Food Chem. (2005) 90:1-8. doi: 10.1016/j.foodchem.2003. 08.023
47. Elkhalifa AE, Schiffler B, Bernhard R. Effect of fermentation on the starch digestibility, resistant starch and some physicochemical properties of sorghum flour. Nahrung. (2004) 48:91-4. doi: 10.1002/food.200300322

48. Zeng Z, Liu C, Luo S, Chen J, Gong E. The profile and bioaccessibility of phenolic compounds in cereals influenced by improved extrusion cooking treatment. PLOS ONE. (2016) 11:e0161086. doi: 10.1371/journal.pone.0161086

49. Pontonio E, Dingeo C, Gobbetti M, Rizzello CG. Maize milling by-products: from food wastes to functional ingredients through lactic acid bacteria fermentation. Front Microbiol. (2019) 10:561. doi: 10.3389/fmicb.2019.00561

50. Chu J, Zhao H, Lu Z, Lu F, Bie X, Zhang C. Improved physicochemical and functional properties of dietary fiber from millet bran fermented by Bacillus natto. Food Chem. (2019) 294:79-86. doi: 10.1016/j.foodchem.2019.05.035

51. Zhu F, Du B, Xu B. Superfine grinding improves functional properties and antioxidant capacities of bran dietary fibre from Qingke (hull-less barley) grown in Qinghai-Tibet Plateau, China. J Cereal Sci. (2015) 65. doi: $10.1016 /$ j.jcs.2015.06.006

Conflict of Interest: The authors declare that the research was conducted in the absence of any commercial or financial relationships that could be construed as a potential conflict of interest.

Publisher's Note: All claims expressed in this article are solely those of the authors and do not necessarily represent those of their affiliated organizations, or those of the publisher, the editors and the reviewers. Any product that may be evaluated in this article, or claim that may be made by its manufacturer, is not guaranteed or endorsed by the publisher.

Copyright $\odot 2022$ Xiao, Li, Xiong, Tui, Zhu and Zhang. This is an open-access article distributed under the terms of the Creative Commons Attribution License (CC $B Y)$. The use, distribution or reproduction in other forums is permitted, provided the original author(s) and the copyright owner(s) are credited and that the original publication in this journal is cited, in accordance with accepted academic practice. No use, distribution or reproduction is permitted which does not comply with these terms. 